Forum 2019 · 34:570

https://doi.org/10.1007/s12312-019-00709-7

Online publiziert: 6. November 2019

(c) Springer Medizin Verlag $\mathrm{GmbH}$, ein Teil von

Springer Nature 2019

\section{bremer}

krebsgesellschaft

Bremer Krebsgesellschaft e.V.

Bremen, Deutschland

\title{
Schau mich an - ein Fotoprojekt der besonderen Art
}

führte Stephan Pregizer von German Cancer Survivors, Berlin. Seiner hohen professionellen Kompetenz und der Sensibilität für das Thema Krebs ist es zu verdanken, dass die 200 Gäste einen tiefen Einblick in das Fotoprojekt erhielten und sich davon berühren ließen.

\section{Wie alles begann}

Begonnen hat alles vor fünf Jahren: Peggy Wentzek, engagiert in der Selbsthilfegruppe für junge Frauen mit Brustkrebs, hatte die Idee, in Bremen ein Fotoprojekt für Frauen in der Chemotherapie auf die Beine zu stellen. „Am meisten fürchtete ich mich vor der Chemotherapie und davor, dass ich meine schönen langen Haare verliere." Peggy Wentzek drückt aus, was viele Frauen in dieser Situation bewegt. Die Bremer Krebsgesellschaft vermittelte den Kontakt zu der ebenfalls betroffenen Fotokünstlerin Claudia A. Cruz, zu Senta Bonneval, die in der Bremer Krebsgesellschaft seit vielen Jahren Schreibwerkstätten leitet, und zu Gabriele Strangemann, Kuratoriumsmitglied und Inhaberin der Parfümerie Zarga. Das Fotoprojekt sollte betroffene Frauen unterstützen und ihr Selbstwert stärken. Jeweils sieben Frauen stellen sich seitdem in Ein-Tages-Projekten mutig der Kamera von Fotokünstlerin Claudia A. Cruz; sie zeigen, dass sie auch ohne Haare schön sind und „ihre Frau stehen“.
Es blieb nicht bei den Fototerminen: Die teilnehmenden Frauen wollten mit den Bildern an die Öffentlichkeit gehen und ein Zeichen gegen die Sprachlosigkeit setzen, die Krebs heute immer noch umgibt. Zur ersten Fotoausstellung kamen über 100 Menschen. Weitere Ausstellungen folgten.

Das große Interesse hat die Frauen ermutigt, einen Bildband mit persönlichen Zitaten der teilnehmenden Frauen herauszugeben.

Auf dem German Survivors Day der Deutschen Krebsstiftung im Juni 2018 in Berlin entstand dann noch die Idee, das Fotoprojekt mit der Kamera zu begleiten.

Beides - Bildband und Film - sind jetzt veröffentlicht und zeigen eindrucksvoll die Stärke und den Mut der Frauen. Der Bildband kann bei der Bremer Krebsgesellschaft erworben werden und einen Einblick in den Film gibt es unter https:// www.bremerkrebsgesellschaft.de/

Der Bildband ist bei der Bremer Krebsgesellschaft erhältlich.

\section{Korrespondenzadresse}

\section{Marie Rösler}

Bremer Krebsgesellschaft e.V.

Am Schwarzen Meer 101-105, 28205 Bremen,

Deutschland

roesler@bremerkrebsgesellschaft.de 